\title{
Pengetahuan dan Adaptasi Petani Kopi terhadap Perubahan Iklim di Kecamatan Air Hitam Kabupaten Lampung Barat
}

\author{
Abdul Mutolib ${ }^{*}$, Ali Rahmat ${ }^{2}$, Tita Sumiati ${ }^{3}$ \\ ${ }^{1,3}$ Program Studi Magister Agribisnis, Program Pascasarjana Universitas Siliwangi \\ ${ }^{2}$ Pusat Penelitian Limnologi, Lembaga Ilmu Pengetahuan Indonesia \\ *Koresponden email: amutolib24@yahoo.com, abdul.mutolib@unsil.ac.id
}

Diterima: 8 September 2021

Disetujui: 11 Oktober 2021

\begin{abstract}
Climate change has caused production declines and crop failures in some agricultural commodities. This study aims to identify the level of knowledge, adaptation practices, and types of protective trees used by coffee farmers in dealing with climate change. The research was carried out in Rigis Jaya Village, West Lampung District from May to July 2021. The number of respondents was 80 coffee farming households. Respondents were determined through a simple random sampling approach. The data collected consists of qualitative and quantitative data. Data collection was carried out through the survey method. The results of the study illustrate that coffee farmers have realized that climate change has occurred. $60 \%$ of coffee farmers are aware of climate change in the last 1-5 years and $20 \%$ of coffee farmers are more than 5 years old. From mitigation practices, $25 \%$ of coffee farmers mitigate climate change. Climate change mitigation practices carried out by farmers are through the use of superior coffee varieties, planting shade trees, setting coffee spacing, making vents, and utilizing the remaining coffee husks to increase soil fertility and moisture. There are 14 types of shade trees planted by farmers consisting of legumes and non-legume trees. Petai (Parkia speciosa) is the most widely planted shade tree in coffee plantations with $45 \%$ of the total respondents.
\end{abstract}

Keywords: farmers, robusta coffee, knowledge, adaptation, climate change

\begin{abstract}
Abstrak
Sektor pertanian yang bergantung dengan alam sangat rentan terhadap perubahan iklim. Perubahan iklim menyebabkan penurunan produksi dan gagal panen diberbagai wilayah. Penelitian ini bertujuan mengidentifikasi tingkat pengetahuan (knowledge), praktik adaptasi (adaptation), dan jenis pohon pelindung yang digunakan petani kopi dalam menghadapi perubahan iklim. Penelitian dilaksanakan di Pekon Rigis Jaya Kabupaten Lampung Barat pada Mei hingga Juli 2021. Jumlah responden sebanyak 80 rumah tangga petani kopi. Responden ditentukan melalui pendekatan simple random sampling. Data yang dikumpulkan terdiri dari data kualitatif dan kuantitatif. Pengumpulan data dilakukan melalui metode survei. Hasil penelitian memberikan gambaran bahwa petani kopi telah menyadari telah terjadi perubahan iklim. Sebanyak 60\% petani kopi menyadari perubahan iklim sejak 1-5 tahun terakhir dan sebanyak $20 \%$ petani lebih dari 5 tahun terakhir. Dari praktik mitigasi, hanya $25 \%$ petani yang menerapkan mitigasi perubahan iklim. Praktik mitigasi perubahan iklim yang dilakukan petani melalui penggunaan varietas kopi unggul, penanaman pohon pelindung, pengaturan jarak tanam kopi, pembuatan lubang angin, serta pemanfaatan sisa kulit kopi untuk meningkatkan kesuburan dan kelembaban tanah. Terdapat 14 jenis pohon pelindung yang ditanam petani yang terdiri dari pohon legum dan non-legum. Petai (Parkia speciosa) adalah pohon pelindung yang paling banyak ditanam pada kebun kopi dengan jumlah $45 \%$ dari total responden.
\end{abstract}

Kata Kunci: petani, kopi robusta, pengetahuan, adaptasi, perubahan iklim

\section{Pendahuluan}

Sub sektor perkebunan menjadi urutan pertama sebagai penyumbang Pendapatan Domestik Bruto (PDB) dari sektor pertanian pada tahun 2019 berdasarkan laporan tahunan Badan Pusat Statistik. Kontibusi yang diberikan sebesar 3,27 persen terhadap total PDB dan sebesar 25,71 persen terhadap sektor pertanian, kehutanan, dan perikanan. Menurut data dari Badan Pusat Statistik (BPS) tahun 2019 luas lahan untuk sektor pertanian di Indonesia hingga tahun 2018 mencapai 7,1 juta hektar.

Pembangunan pertanian khususnya subsektor perkebunan menghadapi berbagai masalah. Pertambahan penduduk menyebabkan alih fungsi lahan sehingga lahan produktif perkebunan semakin sempit. Pada hakikatnya sektor perkebunan merupakan sektor unggulan pertanian di Indonesia. Terbukti beberapa komoditas perkebunan di Indonesia mampu menyerap tenaga kerja yang besar, memberikan 
pendapatan yang layak serta memiliki nilai ekonomi di pasar internasional [1]. Indonesia memiliki banyak komoditas perkebunan andalan, salah satunya adalah kopi Robusta.

Kopi khususnya Robusta merupakan salah satu komoditas perkebunan yang digemari baik dalam dan luar negeri. Indonesia terkenal sebagai salah satu sentra kopi dunia dimana beberapa kopi asal Indonesia sangat populer dan digemari konsumen di luar negeri. Komoditas kopi memiliki nilai ekonomis yang tinggi. Selain itu kopi mampu menciptakan lapangan pekerjaan serta sumber devisa bagi negara. Tingginya minat konsumen dalam dan luar negeri terhadap kopi mendorong tumbunhnya agroindustry kopi baik skala kecil hingga besar [2]. Pada tahun 2020 produksi kopi di Provinsi Lampung mencapai angka 118.149 ton. Provinsi Lampung menempati urutan kedua sebagai produsen kopi terbesar di Indonesia pada tahun 2020 setelah Provinsi Sumatera Selatan. Tingginya produksi dan luas perkebunan kopi di Provinsi Lampung di dukung ketersediaan lahan yang sesuai, iklim, serta kondisi geografis perbukitan sehingga cocok untuk budidaya tanaman kopi Robusta. Sentra produksi kopi Lampung terletak di Kabupaten Lampung Barat. Pada tahun 2018, Kabupaten Lampung Barat menghasilkan kopi Robusta sebanyak 52.572 ton pada tahun $2018[3]$.

Meskipun menempati posisi teratas sebagai sentra kopi di Lampung, produksi kopi Robusta Lampung Barat dinilai masih fluktuatif. Salah satu penyebabnya adalah perubahan cuaca atau iklim. Climate change atau perubahan iklim yang terjadi erat kaitannya dengan fenomena pemanasan global yang terjadi dalam beberapa decade terakhir. Pemanasan global yang terjadi di dunia disebabkan meningkatnya suhu bumi akibat fenomena efek rumah kaca atau greenhouse effect [4] [5]. Fenomena perubahan iklim menyebabkan ketidakpastian musim, serta curah hujan. Hal tersebut sangat berdampak terhadap sektor pertanian khsusunya tanaman kopi. Kopi memiliki kerentanan terhadap perubahan iklim. Perubahan iklim dapat mempengaruhi produksi kopi dan berpengaruh terhadap kualitas dan harga kopi itu sendiri. Perubahan iklim mampu memberikan tekanan kepada petani kopi yang berhubungan dengan tingkat marjinalitas rumah tangga petani secara ekonomi [6].

Terkait fenomena tersebut, sangat diperlukan adanya upaya adaptasi yang dilakukan oleh petani kopi dalam bentuk praktik nyata pada kegaitan budidaya melalui pengetahuan, sikap dan keterampilannya. Seiring berjalannya waktu, perilaku petani (knowledge, attitude and practice) dalam berbudidaya kopi juga harus turut ditingkatkan, hal tersebut bertujuan untuk tetap meningkatkan produksi kopi akibat dampak perubahan iklim. Berdasarkan pernyataan di atas, penelitian ini bertujuan mengidentifikasi tingkat pengetahuan (knowledge), praktik adaptasi (adaptation), dan jenis pohon pelindung yang digunakan petani kopi dalam menghadapi perubahan iklim di Kecamatan Air Hitam Kabupaten Lampung Barat.

\section{Metode Penelitian}

\section{Lokasi dan waktu penelitian}

Secara administrasi, penelitian dilaksanakan di Pekon Rigis Jaya yang terletak di Kabupaten Lampung Barat khususnya Kecamatan Air Hitam. Penentuan Pekon Rigis Jaya sebagai lokasi penelitian dilakukan secara sengaja (purposive) dengan beberapa alasan, yaitu: 1) Pekon Rigis Jaya merupakan salah satu sentra kopi dengan branding "Kampung Kopi” Lampung, 2) Lokasi Pekon Rigis Jaya dekat dengan Hutan Kemasyarakatan yang masih menerapkan budidaya kopi campuran. Waktu penelitian dilaksanakan pada bulan Mei-Juli 2021.

\section{Design dan metode penelitian}

Penelitian tentang adaptasi petani terhadap perubahan iklim menggunakan pendekatan penelitian kualitatif dan metode survei. Penelitian dengan pendekatan kualitatif digunakan agar dapat memberikan gambaran detail dan mendalam tentang permasalahan yang dihadapi petani terhadap fenomena perubahan iklim. Ciri penelitian kualitatif adalah proses pengumpulan dan analisis data berupa kata-kata (lisan ataupun tulisan) dan perbuatan serta tingkah laku manusia dan tidak berupaya mengkuantifikasinya menadi sebuah data atau angka [7].

\section{Sumber data, pengumpulan data, dan responden penelitian}

Data yang digunakan dalam penelitian ini terdiri dari jenis data primer dan sekunder. Data primer merupakan data yang diperoleh secara langsung dari narasumber tanpa perantara pihak ketiga atau pihak lainnya. Data primer dalam penelitian ini dikumpulkan melalui proses melalui survei terhadap petani kopi, wawancara dengan key informant, serta melakukan observasi lapangan. Sumber data sekunder dapat berasal dari buku, laporan, hasil penelitian serta sumber lain yang relevan dengan topik penelitian. Responden penelitian adalah petani kopi yang berjumlah 40 rumah tangga petani. Metode pengumpulan menggunakan wawancara dengan kuesioner untuk responden dan panduan wawancara untuk key informant. 


\section{Teknik analisis data}

Pada penelitian kualitatif, analisis ini dilakukan setiap saat selama penelitian berlangsung [7]. Kegiatan pengumpulan dan analisis data dalam penelitian ini tidak terpisah satu sama lain. Keduanya berlangsung secara simultan dan prosesnya berbentuk siklus [8]. Oleh karena itu, penelitian ini menggunakan analisis data model interaktif yang terdiri dari tiga tahap yaitu reduksi data, display data, dan penarikan kesimpulan/verifikasi [9].

\section{Hasil dan Pembahasan \\ Pengetahuan petani terhadap perubahan iklim}

Pengetahuan petani dalam perubahan iklim merupakan aspek mendasar dalam upaya mitigasi serta beradaptasi terhadap perubahan iklim. Petani kopi yang memiliki pengetahuan baik terhadap perubahan iklim akan berupaya dalam melakukan adaptasi untuk meminimalisir dampaknya tehadap usahatani kopi. Meskipun demikian, usahatani kopi yang berada dikawasan bukit atau pegunungan dengan vegetasi pelindung relatif baik memberikan keuntungan dari aspek suhu dan ketersediaan air.

Tanaman kopi yang merupakan komoditas perkebunan (tanaman tahunan) cenderung tahan terhadap kekeringan. Tanaman kopi memiliki usia produktif kopi adalah 5 hingga 20 tahun memiliki perakaran yang kuat terhadap perubahan iklim terutama kesediaan air serta cenderung tahan terhadap kekeringan. Meskipun relatif tahan terhadap kekeringan dan ketersediaan air yang terbatas. Perubahan iklim terutama kekeringan karena tidak pastinya musim kemarau dan hujan berdampak serius pada produktivitas kopi. Musim hujan yang tidak menentu menyebabkan rontoknya bunga tanaman kopi sehingga calon buah kopi akan rontok dan busuk, sehingga ini menyebabkan rendahnya produktivitas tanaman kopi. Perubahan iklim berdampak serius pada produksi tanaman kopi. Tingkat pengetahuan petani kopi terhadap perubahan iklim ditampilkan pada Tabel 1.

Tabel 1. Pengetahuan petani kopi terhadap perubahan iklim

\begin{tabular}{lccc}
\hline No. & Peryataan & Jawaban & Persentase (\%) \\
\hline 1. & Petani mengetahui perubahan iklim & Ya & $100 \%$ \\
& & Tidak & - \\
\hline 2. & Merasakan perubahan iklim & Tidak tahu & $10 \%$ \\
& & $1-2$ Tahun & $25 \%$ \\
& $3-5$ Tahun & $45 \%$ \\
& >5 Tahun & $20 \%$ \\
\hline
\end{tabular}

Sumber : Data primer (2021)

Hasil penelitian memberikan gambaran bahwa keseluruhan responden (petani kopi) menyadari telah terjadi perubahan iklim. Perubahan iklim telah menjadi fenomena yang dipahami petani kopi di Pekon Rigis Jaya. Dari aspek waktu (lama) perubahan iklim, responden memberikan jawaban yang berbeda. Terdapat $10 \%$ petani yang tidak mengetahui kapan waktu pasti perubahan iklim terjadi. Sebanyak $25 \%$ petani kopi menyadari perubahan iklim telah dirasakan sejak 1-2 tahun terakhir, kemudian sebanyak 45\% petani menyadari bahwa perubahan iklim telah dirasakan sejak 3-5 tahun terakhir, dan sebanyak $20 \%$ petani menjelaskan bahwa mereka telah merasakan perubahan iklim lebih dari 5 tahun terakhir. Indikator yang paling banyak digunakan petani dalam mengidentifikasi perubahan iklim adalah peningkatan suhu, bergesernya waktu musim hujan dan kemarau, dan ketersediaan air.

Dari aspek dampak, perubahan iklim berdampak negatif pada usahatani kopi. Dampak perubahan iklim yang dirasakan petani antara lain terjadinya peningkatan serangan hama penyakit pada tanaman kopi dan penurunan produksi (hasil panen). Perubahan iklim terhadap usahatani kopi ditampilkan pada Tabel 2.

Tabel 2. Dampak perubahan iklim terhadap usahatani kopi

\begin{tabular}{lllc}
\hline No. & \multicolumn{1}{c}{ Peryataan } & \multicolumn{1}{c}{ Jawaban } & Persentase (\%) \\
\hline 1. & Perubahan Iklim yang dirasakan & Perubahan curah hujan & $80 \%$ \\
& & Perubahan suhu yang meningkat & $20 \%$ \\
2. & Perubahan Iklim menyebabkan & Ya & $10 \%$ \\
& peningkatan serangan hama penyakit & Tidak & $90 \%$ \\
3. & Perubahan Iklim menyebabkan & Ya & $100 \%$ \\
& penurunan produksi (hasil panen) & Tidak & - \\
\hline
\end{tabular}

Sumber : Data primer (2021) 
Sebagian besar petani kopi menyadari perubahan iklim melalui perubahan curah hujan dengan persentase sebanyak $80 \%$. Perubahan curah hujan ini ditandai dari bergesernya musim hujan dan kemarau. Kemudian sebanyak $20 \%$ petani menyadari perubahan iklim dari perubahan suhu udara yang terus meningkat. Udara di Pekon Rigis Jaya saat ini dinilai lebih panas dibandingkan beberapa tahun yang lalu. Hal ini menjadi parameter pengetahuan petani bahwa perubahan iklim telah terjadi dalam beberapa tahun terakhir. Dari aspek hama penyakit, perubahan iklim memiliki dampak terhadap peningkatan hama dan penyakit pada tanaman kopi. Meskipun tidak signifikan, perubahan iklim telah menyebabkan peningkatan hama dan penyakit (10\% petani). Kemudian sebanyak $90 \%$ petani tidak merasakan peningkatan hama dan penyakit secara signifikan akibat perubahan iklim.

Dari aspek produksi, perubahan iklim memberikan dampak negatif terhadap produksi tanaman kopi. Seluruh responden $(100 \%)$ menyatakan bahwa perubahan iklim telah menyebabkan penurunan produksi kopi secara signifikan. Dari hasil wawancara diperoleh fakta bahwa pada tanaman kopi masa atau waktu yang paling krusial adalah saat tanaman kopi berbunga. Pada saat tanaman kopi berbunga, tanaman kopi kurang tahan apabila terkenan hujan dengan intensitas tinggi. Hal ini menyebabkan bunga kopi rontok dan calon buah kopi busuk. Dalam beberapa tahun intensitas hujan tidak menentu waktu dan volumenya, sehingga menyebabkan penurunan produksi kopi hingga 30\%-50\%.

\section{Adaptasi petani terhadap perubahan iklim}

Adaptasi dapat diartikan sebagai sebuah upaya yang dilakukan oleh manusia untuk mengatasi suatu masalah terutama hal-hal baru diluar kebiasaan yang dihadapi manusia. Petani sangat bergantung pada iklim dan alam, oleh karena itu perubahan iklim dan alam mengharuskan adaptasi untuk mampu mengatasi masalah iklim dan alam. Adaptasi petani berkaitan dengan upaya baik secara praktik, proses serta sistem untuk mengurangi dampak negatif dari perubahan iklim saat ini dan dimasa mendatang. Adaptasi petani terhadap perubahan alam dan iklim dapat berlangsung secara terencana maupun tidak terencana berdasarkan masalah yang dihadapi. Adaptasi petani terhadap perubahan iklim dipengaruhi oleh banyak faktor diantaranya faktor ekonomi, sosial, politik, budaya, ekologi dan kelembagaan. Faktor-faktor ini pada mempengaruhi interaksi manusia dengan manusia serta dengan lingkungan [10], [11].

Adaptasi petani terhadap perubahan iklim bergantung pada beberapa aspek seperti kemampuan atau kapasitas adaptif petani, kemapanan ekonomi, ketrampilan petani, ketersediaan sumber daya keluarga, serta ketersediaan lembaga yang mendukung implementasi strategi adaptasi petani yang efektif dan efisien [12], [13]. Salah satu aspek penting yang memperngaruhi kemampuan adaptasi petani terhadap perubahan iklim adalah kapasitas adaptif petani. Kapasitas adaptif adalam kemampuan yang dimiliki oleh petani untuk berubah sesuai dengan tuntutan alam atau iklim. Kapasitas adaptif petani dipengaruhi banyak faktor diantaranya pengetahuan terhadap perubahan iklim, kepemilikan terhadap asset, akses terhadap teknologi dan fasilitas, kebijakan pemerintah, kemantapan kelembagaan serta persepsi petani terhadap perubahan iklim.

Persepsi dan pengetahuan petani terhadap perubahan iklim merupakan salah satu faktor kunci yang mempengaruhi kekampuan adaptif dalam strategi adaptasi perubahan iklim. Sedangkan persepsi petani terhadap perubahan iklim dipengaruhi beberapa hal diantaranya persepsi terhadap dampak perubahan iklim, sumberdaya atau asat yang dikuasai, faktor norma dan budaya, keberadaan lembaga serta faktor politik [14], [15]. Persepsi petani terhadap dampak perubahan iklim yang tinggi akan mendukung perilaku adapatsi pterhadap perubahan iklim petani kopi. Petani kopi yang melakukan adaptasi perubahan iklim ditampilkan pada Gambar 1.

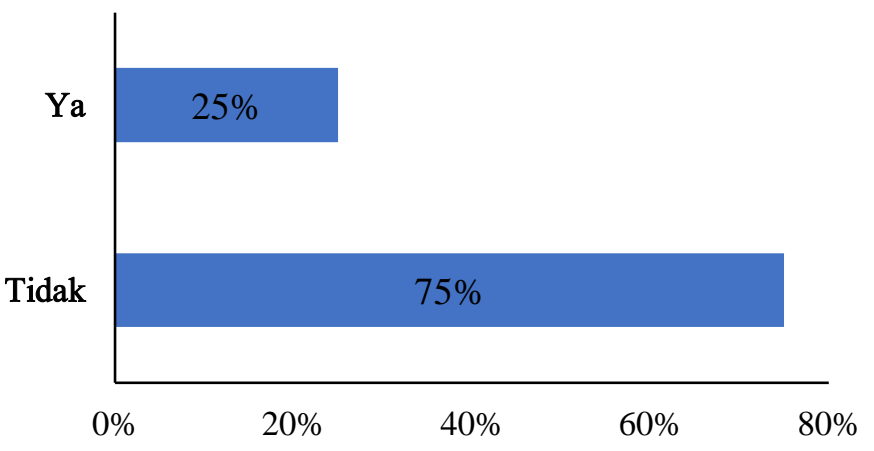

Gambar 1. Jumlah petani yang melakukan adaptasi perubahan iklim Sumber : Data primer (2021) 
Pada Gambar 1 diperoleh informasi bahwa dari keseluruhan responden hanya 25\% petani yang melakukan adaptasi terhadap perubahan iklim. Petani kopi yang tidak melakukan mitigasi terhadap perubahan iklim sebanyak 75\%. Meskipun jumlah petani yang melakukan mitigasi terhadap perubahan iklim rendah, namun pada kenyataannya hampir seluruh petani telah melakukan upaya mitigasi tersebut tetapi petani tidak menyadari bahwa upaya yang dilakukan merupakan bagian dari mitigasi terhadap perubahan iklim. Beberapa contoh aktivitas usahatani yang telah dilakukan sebagai mitigasi terhadap perubahan iklim namun belum dipahami petani sebagai bagian dari mitigasi adalah penanaman pohon pelindung, penanaman tanaman kopi robusta dengan jarak terstandar, pembuatan lubang angin, serta penggunaan sisa kulit kopi untuk meningkatkan kesuburan dan kelembaban tanah pada perkebunan kopi.

\section{Praktek kebun kopi campuran}

Persentase petani yang menerapkan praktik mitigasi perubahan iklim masih rendah (25\%), namun tanpa disadari petani telah melakukannya. Hanya saja petani belum meneyadari tindakannya masuk dalam upaya mitigasi perubahan iklim. Beberapa petani menggunakan jenis varietas kopi yang tahan terhadap hujan sehingga bunga tanaman kopi tidak rontok. Selain dari aspek varietas, hampir semua petani kopi menerapkan sistem kebun kopi campuran yang mana selain tanaman kopi, petani juga menanam pohon pelindung diareal kebun kopi. Kebun kopi yang memiliki pohon pelindung disebut sebagai kebun kopi campuran.

Kebun kopi campuran yang dikembangkan petani kopi di Pekon Rigis Jaya umumnya merupakan kombinasi kopi dengan beberapa pohon yang memiliki berbagai manfaat. Pohon pelindung yang ditanam disesuaikan dengan kebutuhan dan keinginan petani. Beberapa petani menggunakan pohon pelindung yang menghasilkan buah agar dapat dipanen. Berapa petani menanman pohon pelindung dari jenis kayu serta beberapa petani menanam pohon pelindung agar dapat dimanfaatkan daunnya untuk pakan ternak [16]. Jenis pohon pelindung pada tanaman kopi dikelompokan dalam kelompok multi purpose tree species (MPTS) yang mana tanaman tersebut memiliki manfaat serbaguna yaitu sebagai pohon pelindung kopi, menghasilkan buah, menghasilkan kayu, pakan ternak, serta dapat menyuburkan tanah di areal perkebunan kopi.

Dari jenis manfaatnya, pohon pelindung yang ditanam petani kopi di Pekon Rigis Jaya dikelompokkan dalam dua jenis yaitu pohon pelindung legum dan non-legum. Pohon pelindung dari jenis legum merupakan pohon yang memiliki bintil akar sehingga mampu menghasilkan nitrogen yang berdampak pada kesuburan tanah [17]. Oleh karena itu banyak petani yang menanam jenis pohon pelindung dari jenis legum. Namun, banyak juga petani yang memilih pohon pelindung dari jenis non legum untuk memperoleh manfaat terutama buah atau kayu yang memiliki nilai ekonomis tinggi. Tanaman legum yang paling sering ditanam petani di Indonesia untuk meningkatkan kesuburan tanah adalah Gamal (Gliricidia sepium) dan Dadap (Erythrina subumbrans). Jenis pohon pelindung yang ditanam pada perkebunan kopi ditampilkan pada Tabel 3.

Tabel 3. Jenis pohon pelindung yang ditanam pada perkebunan kopi

\begin{tabular}{lllc}
\hline No. & \multicolumn{1}{c}{$\begin{array}{c}\text { Nama Pohon } \\
\text { Pelindung }\end{array}$} & \multicolumn{1}{c}{$\begin{array}{c}\text { Nama Latin } \\
\text { Adopter }\end{array}$} \\
\hline 1. & Daun Afrika & Vernonia amygdalina & 2 \\
2. & Sengon & Albizia chinensis & 6 \\
3. & Randu & Ceiba pentandra & 4 \\
4. & Pisang & Musa paradisiaca & 2 \\
5. & Medang & Phoebe angustifolia & 1 \\
6. & Petai & Parkia speciosa & 9 \\
7. & Gamal & Gliricidia sepium & 2 \\
8. & Lamtoro & Leucaena leucocephala & 5 \\
9. & Nangka & Artocarpus heterophyllus & 7 \\
10. & Dadap & Erythrina variegata & 6 \\
11. & Mahoni & Swietenia mahagoni & 3 \\
12. & Alpukat & Persea americana & 3 \\
13. & Kemiri & Aleurites moluccanus & 1 \\
14. & Durian & Durio zibethinus & 1 \\
\hline
\end{tabular}

Sumber : Data primer (2021)

Pada Tabel 3 diperoleh informasi bahwa terdapat 14 jenis pohon pelindung yang ditanam bersama tanaman kopi. Petai (Parkia speciosa) adalah pohon pelindung yang paling banyak ditanam pada kebun kopi dengan jumlah $45 \%$ dari total responden. Selain petai, pohon nangka (Artocarpus heterophyllus) 
banyak dipilih responden sebagai pohon pelindung dengan persentase $35 \%$. Petai dan nangka dipilih sebagai pohon pelindung karena menghasilkan buah yang memiliki nilai ekonomis tinggi. Selanjutnya, pohon pelindung lain yang banyak ditanam petani kopi Robusta adalah pohon Sengon (Albizia chinensis) dan Dadap (Erythrina variegata) yang ditanam oleh 30\% responden. Pohon dadap memiliki keunggulan pada pertumbuhannya yang cepat. Selain itu pohon sengon dan dadap termasuk jenis tanaman legum yang bermanfaat bagi kesuburan tanah. Pohon pelindung dari jenis legum (dadap) berpengaruh terhadap produktivitas kopi yang mana jumlah unsur hara $(\mathrm{N}, \mathrm{P}, \mathrm{K})$ yang terangkut saat panen buah dikembalikan oleh serasah guguran (daun) pohon pelindung yang menyuburkan kebun kopi [18].

\section{Kesimpulan}

Petani kopi telah menyadari telah terjadi perubahan iklim. Sebanyak $10 \%$ petani kopi tidak mengetahui sejak kapan perubahan iklim terjadi. Kemudian, $25 \%$ petani kopi menyadari bahwa perubahan iklim sejak 1-2 tahun terakhir, sebanyak $45 \%$ petani menyadari bahwa perubahan iklim sejak 3-5 tahun terakhir, dan sebanyak $20 \%$ petani telah merasakan perubahan iklim lebih dari 5 tahun terakhir. Indikator yang paling banyak digunakan oleh petani dalam memperediksi perubahan iklim adalah peningkatan suhu, bergesernya waktu musim hujan dan kemarau, serta ketersediaan air. Sebanyak $25 \%$ petani melakukan mitigasi terhadap perubahan iklim untuk melindungi usahatani kopi. Praktik mitigasi perubahan iklim yang dilakukan petani kopi antara lain melalui penggunaan varietas kopi unggul, penanaman pohon pelindung, pengaturan jarak tanam kopi, pembuatan lubang angin, serta pemanfaatan sisa kulit kopi untuk meningkatkan kesuburan dan kelembaban tanah. Terdapat 14 jenis pohon pelindung yang ditanam petani yang terdiri dari pohon legum dan non-legum. Petai (Parkia speciosa) adalah pohon pelindung yang paling banyak ditanam pada kebun kopi dengan jumlah $45 \%$ dari total responden. Petai dipilih sebagai pohon pelindung karena menghasilkan buah yang memiliki nilai ekonomis tinggi.

\section{Daftar Pustaka}

[1] T.L. Novianti, "Pengaruh Pendapatan Terhadap Alokasi Konsumsi Rumah Tangga Petani Karet di Kecamatan Rimbo Ilir Kabupaten Tebo". Jurnal. Program Studi Agribisnis Universitas Jambi, 2018

[2] P. Rahardjo, "Panduan Budi Daya dan Pengolahan Kopi Arabika dan Robusta," Jakarta, Penerbit Swadaya, 2012.

[3] [Badan Pusat Statistik] Provinsi Lampung. Provinsi Lampung dalam Angka 2020. Bandar Lampung, 2020.

[4] K. Murniati, A. Mutolib, "The impact of climate change on the household food security of upland rice farmers in Sidomulyo, Lampung Province, Indonesia," Biodiversitas ., vol. 21 (8), 3487-3493, 2020.

[5] A. Rahmat, M.K. Zaki, I. Effendi, A. Mutolib, H. Yanfika, and I. Listiana, "Effect of global climate change on air temperature and precipitation in six cities in Gifu Prefecture, Japan," Journal of Physic Conference Science., 1155, 012070, 2019.

[6] H.P. Widayat, and A. Baihaqi, "Dampak perubahan iklim terhadap produksi, kualitas hasil dan pendapatan petani kopi arabika di Aceh Tengah,” Jurnal Agrisep, vol. 16, 2, 8-16, 2015.

[7] Afrizal, "Metode Penelitian Kualitatif: Sebuah Upaya Mendukung Penggunaan Penelitian Kualitatif dalam Berbagai Disiplin Ilmu," Jakarta: Raja Grafindo Persada, 2015.

[8] J. W. Creswell, "Research design Qualitative quantitative and mixed methods approaches. Research design Qualitative quantitative and mixed methods approaches (Fourth), " Thousand Oaks, California: SAGE Publications, 2014.

[9] M.B. Miles, A.M. Huberman, J. Saldana, "Qualitative Data Analysis: A Methods Sourcebook," California, USA. SAGE Publications, 2014.

[10] I. Otto-Banaszak, P. Matczak, J. Wesseler, and F. Wechsung, "Diferent perceptions of adaptation to climate change: A mental model approach applied to the evidence from expert interviews," Reg Environ Change., vol. 11, 217-228, 2011.

[11] Jr. JG. Arbuckle, L.S. Prokopy, T. Haigh, J.Hobbs, T. Knoot, C. Knutson, A. Loy, A.S. Mase, J. McGuire, L.W. Morton, J. Tyndall, and M. Widhalm, "Climate change beliefs, concerns, and attitudes toward adaptation and mitigation among farmers in the Midwestern US," Climatic Change., vol. 117, 943-50, 2013.

[12] P. Maponya, and S. Mpandeli, "Perception of farmers on climate change and adaptation in Limpopo province of South Africa," J. Hum. Ecol, vol. 42, 3,283-288, 2013.

[13] M.T. Niles, M. Lubell, and M. Brown, "How limiting factors drive agricultural adaptation to climate change," Agriculture, Ecosystems and Environment., vol. 200, 178-85, 2015. 
[14] J. Z. McDowell, and J.J. Hess, "Accessing adaptation: Multiple stressors on livelihoods in the Bolivian highlands under a changing climate," Global Environmental Change, vol. 22, 342-352, 2012.

[15] O. A. Obayelu, O. A. Adepoju, and T. Idowu, T, "Factors inluencing farmers' choices of adaptation to climate change in Ekiti State, Nigeria," J. of Agric. and Environment for International Development., vol. 108 (1), 3-16, 2014.

[16] D. Suherman, I. Herdiawan, "Tanaman Legum Pohom Desmodium rensonii sebagai Tanaman Pakan Ternak Bermutu," Pastura., Vol. 4 No. 2, 100 - 104, 2015.

[17] R. Sari, R. Prayudyaningsih, "Rhizobium: Pemanfaatannya Sebagai Bakteri Penambat Nitrogen," Info Teknis Eboni., vol. 12, 1, 51-64, 2015.

[18] R. Evizal, Tohari, I. D. Prijambada, and J.Widada, "Peranan pohon pelindung dalam menentukan produktivitas kopi," Jurnal Agrotropika., vol. 17, 1, 19-23, 2010. 